Referencia al citar este artículo:

Calderón, D. y Múnera, C. (2014). La televisión del control neuronal y la teoría moral de los muñecos de trapo: sentidos del cyberpunk y postcyberpunk en el cine, e impacto de la tecnología en la sociedad. Revista TEMAS, 3 (8), 125 - 137.

\title{
La televisión del control neuronal y la teoría moral de los muñecos de trapo: sentidos del cyberpunk y postcyberpunk en el cine, e impacto de la tecnología en la sociedad ${ }^{1}$
}

\author{
Claudia Patricia Múnera ${ }^{2}$ \\ Diego Francisco Calderón Aponte ${ }^{3}$
}

Recibido: 03/06/2014 Aceptado: 11/06/2014

\section{Resumen}

El presente artículo presenta el primer producto de una investigación, cuyo objetivo es tratar de establecer los sentidos de los subgéneros de la ciencia ficción cyberpunk y el postbcyberpunk en el cine, y el impacto de la tecnología en la sociedad, tema ampliamente abordado por estos subgéneros literarios. En primera instancia, se presenta una aproximación sobre qué es cyberpunk y el postcyberpunk, y cómo estos subgéneros literarios de la ciencia ficción han obrado en el cine. Posteriormente, se presenta la semántica estructural y el modelo actancial que establecen cuáles son los sistemas de sentidos encontrados en el cyberpunk y postcyberpunk, para de allí pasar al análisis del impacto de la tecnología en la sociedad a partir de dos películas: Videodrome y Nueve, cada una representativa de cada subgénero.

\section{Palabras clave:}

Cyberpunk, Postcyberpunk, Modelo actancial, Semántica estructural, Posthumano, Libertad-sujeción.

\section{Television of neuronal control and the moral theory of rag dolls: postcyberpunk and cyberpunk meanings in cinema, and impact of technology on society}

\begin{abstract}
This paper presents the first product of a research and aims at establishing the meanings of two subgenres of science fiction in cinema, cyberpunk and postcyberpunk, and the impact of technology in society, a topic widely discussed by these literary subgenres. First, the article approaches cyberpunk and postcyberpunk and portrays how these subgenres of science fiction have worked in movies. Subsequently, the structural semantics and actancial model are presented as they establish the meanings found in the cyberpunk and postcyberpunk. Finally, the article analyzes the impact of technology in society based on two movies: Videodrome and Nueve, as each of them represents each subgenre.
\end{abstract}

\section{Keywords:}

Cyberpunk, Postcyberpunk, Actancial model, Structural Semantics, Posthuman, Liberty-subjection.

1 Artículo de investigación. Sentidos del cyberpunk y postcyberpunk en el cine, e impacto de la tecnología en la sociedad.

2 Licenciada en Idiomas y Especialista en pedagogía y semiótica de la lengua materna, Universidad Industrial de Santander; Master of Arts in Online Education (UNAD Florida). Docente ocasional tiempo completo y líder zonal de la Escuela de Educación, Universidad Nacional Abierta y a Distancia, UNAD. E-mail: claudia.munera@unad.edu.co

3 Economista, filósofo, Investigador Grupo Historia, Archivística y Redes de Investigación, Universidad Industrial de Santander. Magíster en Historia, Universidad Javeriana. Docente ocasional medio tiempo- Escuela de ciencia sociales artes y humanidades, Universidad Abierta y a Distancia, UNAD. Consultor en análisis cualitativo, Teknidata consultores. E-mail: diego.calderon@unad.edu.co 


\section{INTRODUCCIÓN}

El ciberpunk es el espíritu de nuestra era desencantada, es el contrapeso al conservadurismo que en tiempos de depresión intenta imponerse. Es la estética de la banalidad y la crueldad de este mundo [visto en los ochenta] sobre informado y desensibilizado. Naief Yehya (Citado en Cortes, 1998, p.115).

Las páginas que siguen muestran resultados de investigación que busca realizar un análisis de los planteamientos realizados por el cyberpunk y postcyberpunk, obrados a través del séptimo arte por parte de este movimiento estético de la ciencia ficción y entorno al problema del impacto de la tecnología sobre el individuo y la sociedad. El primer momento de la investigación consistía en llegar al planteamiento de una estructura actancial que dé cuenta de las narraciones identificadas y catalogadas dentro del género.

En un primer momento, se explicará qué es el cyberpunk y postcyberpunk, señalando los problemas fundamentales que plantean la narraciones de este género en su apuesta narrativa sobre el impacto de la tecnología en el individuo y la sociedad, para pasar a exponer el segundo punto de anclaje de nuestra investigación: la semántica estructural y el modelo actancial. Después de estas consideraciones contextuales y teóricas, se planteará una estructura actancial que tiene un carácter provisional, ya que el volumen de material fílmico catalogado y analizado va aumentado a medida que avanza la investigación y la filmatogía. Para finalizar, se realizará una exposición de dos películas que hacen parte del catálogo. Dichas exposiciones no tienen la pretensión de ser fichas técnicas de las mismas, ni tampoco completos análisis, sino que intentan ser muestras del cyberpunk, y postcyberpunk conectadas con el análisis estructural.
FOTOGRAMA 1. ¿QUÉ ES EL CYBERPUNK Y POSTCYBERPUNK?

En la década de los 80 del siglo $X X$, un grupo de escritores de ciencia ficción crearon relatos en contextos distópicos y postindustriales de sociedades hipertecnologizadas, en contraposición de la visión utópica de la tecnología que existía (como por ejemplo la que proyectaba la serie los Supersónicos, en inglés The Jetsons ${ }^{4}$ creada en 1962. Dichas narraciones nacieron en el mundo literario y trascendieron al séptimo arte teniendo como eje central la relación semántica estructural: Alta tecnología / Baja calidad de vida. Dicha estructura de significado ha logrado la configuración de relatos de ficción que plantean reflexiones descriptivas del impacto de la tecnología en la sociedad y el individuo, hoy realizadas también desde la filosofía de la tecnología, junto a los estudios de ciencia, tecnología y sociedad (CTS), y el activismo social frente al tema de la obsolescencia programada 5 . El lugar de estas descripciones sobre el impacto de la tecnología, y desde la ciencia ficción, es un futuro distópico y tecnológico en el que la economía corporativa monopoliza el cuerpo, la vida y la existencia.

La apuesta estética del cyberpunk se realizó mostrando cómo la percepción sensorial cambia cuando el cuerpo

4 The Jetsons, o los Supersónicos, como se conocieron en América Látina, es una serie animada creada por Hanna \& Barbera Producciones en 1962. La historia refiere al año 2062, cien años en el futuro del tiempo en que fue creada, la serie trata una versión futurista de la realidad, en la cual una familia de clase media norteamericana vive situaciones cotidianas junto a robots, hologramas, extraterrestres e invenciones tecnológicas que facilitan su diario vivir. Es una de las últimas series en la que se presenta un panorama alentador del futuro, en el que los avances tecnológicos facilitan las tareas cotidianas y se aprecia el amor al progreso.

5 La obsolescencia programada (OP) es uno de los tres pilares que constituyen la sociedad de consumo del siglo XX y XIX: La publicidad, el crédito y OP. De este concepto habló Bruce Stirling, uno de los teóricos y fundares del Cyberpunk. Para saber más sobre este tema, siguiendo la línea multimedia de los textos que soportan la investigación que presenta este artículo véase: Documental Tirar y comprar. Disponible en: http://www.rtve.es/alacarta/videos/ el-documental/documental-comprar-tirar-comprar/1382261/ 
humano es trasformado por la alta tecnología, ya sea con la tecnología de las drogas de diseño (como en la Naranja Mecánica de Stanley Kubrik ${ }^{6}$, la genética (en Gattaca de Andrew Niccol7), la robótica (Yo Robot de Alex Proyas ${ }^{8}$ ), la realidad virtual o ciberespacio (la trilogía de la Matriz de los hermanos Wachows$\mathrm{ki}^{9}$ ), y la biomecánica (eXistenZ de David Cronenberg $\left.{ }^{10}\right)$. Este tipo de estética creó relatos, propuestas musicales, modas en la forma de vestir, convirtiéndose en un movimiento estético underground que se consolidó con la obra literaria y teórica de escritores como William Gibson ${ }^{11}$ y Bruce Sterling ${ }^{12}$, en las que:

Los sentidos juegan también un papel en la estética del ciberpunk, pues el propio cuerpo se convierte en protago-

6 Guionista, director y productor de cine norteamericano, considerado como uno de los más influyentes cineastas del siglo XX. Realizó varias películas consideradas como clásicas del cine, entre las que se encuentran 2001: Odisea en el espacio, La naranja mecánica, Espartaco y El resplandor.

7 Guionista, productor y director de cine neozelandés, reconocido por películas de ciencia ficción como Gattaca y Simone, y películas de tinte político y social como The Truman show y el señor de la guerra.

8 Guionista, director y productor de cine greco-australiano, reconocido por dirigir películas como El cuervo, Dark City y Yo, robot (esta última inspirada en la serie de cuentos del escritor ruso Isaac Assimov). Las escenas de sus películas se caracterizan por presentar paisajes post-apocalípticos creados con el uso de técnicas fotográficas.

9 Andy y Lana Wachowsky, guionistas y directores de cine norteamericanos creadores de la trilogía The Matrix y la franquicia derivada de esta (la serie está compuesta por la saga de 3 películas: The Matrix, The Matrix Reloaded y The Matrix Revolutions, y dos películas más: Animatrix y Dentro de Matrix). Otras películas producidas son $\mathrm{V}$ for vendetta y Cloud Atlas.

10 Guionista, productor de cine y actor Canadiense, conocido como uno de los creadores del género de horror corporal debido a las temáticas de sus producciones cinematográficas, en las que el temor humano a los cambios corporales y las infecciones prevalece. Entre su gran producción cinematográfica de ciencia ficción destacan: La mosca, Scanners, Videodrome y eXintenZ.

11 Escritor norteamericano considerado como el precursor del subgénero de ciencia ficción cyberpunk. Sus escritos se han caracterizado por predecir adelantos tecnológicos propios de la era de información, como el auge de los reality shows y de la realidad virtual a través de los juegos de video y la internet. Entre sus obras más reconocidas están Neuromancer, the Sprawl trilogy, the difference engine $y$ the bridge trilogy.

12 Escritor de ciencia ficción norteamericano, confundador el subgénero cyberpunk y uno de sus principales defensores y promotores. Su antología Mirroshades fue la obra que ayudó a definir este género. Las novelas Involution ocean, Nullaqua y Schismatrix son sus obras más representativas. nista, al ser alterado por las drogas de diseño o la tecnología de los implantes y las prótesis electrónicas. Su esfuerzo por evidenciar todo un mundo sensorial, de una perturbadora sensualidad, provocado por la alteración de los sentidos a través de psicodélicos viajes al fondo de la mente, constituye una verdadera novedad en la CF y confiere un peculiar sabor surrealista a muchos paisajes (Sterling, 1998, p.13).

La palabra Cyberpunk fue usada por primera vez por Bruce Bethke ${ }^{13}$, como título de un cuento publicado en 1983, y un año más tarde Gardner Dozois ${ }^{14}$ utilizó dicha palabra en un artículo publicado en el Washington Post para describir el género de la literatura de ciencia ficción que estaba naciendo de la mano de escritores como Sterling, Cadigan ${ }^{15}$ y Gibson, que en pocos años dejaría de ser término para convertirse en la contracultura anglosajona de los ochenta (Santana Cardoso, 2001). Pero en los noventas el movimiento contracultural dejó de ser una cultura de subsuelo, se suavizó la agresividad visual en las películas, el nihilismo radical desapareció, sus personajes dejaron de ser solitarios para convertirse en individuos de grupo y sociedad, su repertorio se amplió al de la biotecnología y transversalidad tecnológica, y se incluyeron reflexiones éticas a sus crudas descripciones del impacto de la tecnología en la sociedad (Sterling, 1998, p.13).

Este género artístico y cultural no ha partido de cero, las ideas seminales se pueden encontrar en la ciencia ficción de los sesenta, de la mano de autores

13 Escritor e ingeniero norteamericano, conocido por su cuentos Cyberpunk, Maverick, Headcrash y Rebel moon.

14 Escritor y editor de ciencia ficción norteamericano, reconocido por ser el editor jefe de la revista La ciencias ficción de Asimov. En entre sus escritos se encuentran The peacemaker, The visible man y Strange days.

15 Escritora norteamericana, reconocida por sus novelas que buscan explorar la relación entre la mente humana y la tecnología. Su novela más famosa, Mindplayers, sobrepasa la línea entre la realidad y la percepción al ser la mente un lugar real y explorable. 
como J.G Ballard ${ }^{16}$, Brian Aldiss ${ }^{17}$, Philio K. Dick ${ }^{18}$, Tomas Pynchon ${ }^{19}$, Norman Spinrad ${ }^{20}$, John Moorcock ${ }^{21}$, y en los clásicos de la Ciencia ficción visionaria como H.G. Wells ${ }^{22}$, Aldous Huxley ${ }^{23}$, y Olaf Stapledon ${ }^{24}$, para referir solo algunos. Siguiendo el planteamiento de Sterling de la cita anterior, el género pretendió ser una vuelta a los orígenes de la ciencia ficción con herramientas, recursos, y preguntas de la contemporaneidad (Burgos, 2011).

Este tipo de narrativa es una combinación de la novela policial y negra; tanto el cyberpunk clásico como el postcyberpunk introducen personajes marginalizados, solitarios que luchan contra la alienación de la economía corporativa, viven sus existencias en el subsuelo social

16 Escritor de ciencia ficción y ensayista inglés, cuyo trabajo se ha caracterizado por describir escenarios apocalípticos o postapocalípticos. Entre sus novelas se encuentran: El imperio del Sol y Crash, que Cronenberg adaptó posteriormente para su producción cinematográfica.

17 Escritor de ciencia ficción inglés, de los principales representantes de ciencia ficción británica. Entre sus obras se encuentra Cuando la tierra esté muerta (1963), Un mundo devastado (1965) e Invernáculo (1962).

18 Escritor de ciencia ficción norteamericano con una notable carrera que influyó enormemente este género literario. Sus obras se centraban en la política, la metafísica y la sociología a partir de representaciones de gobiernos totalitarios, estados alterados de la conciencia y las empresas monopolíticas. Entre sus principales obras se encuentran ¿Sueñan los androides con ovejas eléctricas?, Tiempo de Marte y fluyan mis lágrimas, dijo el policía.

19 Escritor norteamericano reconocido por sus obras The crying of Lot 49 y Gravity's rainbow.

20 Escritor de ciencia ficción norteamericano, reconocido por las novelas: Incordie a Jack Barron, El juego de la mente y Pequeños héroes, esta última perteneciente al subgénero cyberpunk.

21 Escritor inglés de ciencia ficción y fantasía, y editor de la revista Nuevos mundos. Entre sus principales obras se encuentran Behold the man, New worlds y The condition of Muzack.

22 Escritor, historiador y filósofo inglés, famoso por sus novelas de ciencia ficción y considerado como uno de los precursores de este género. Sus novelas más célebres son: La máquina del tiempo, El hombre invisible, La isla del doctor Moreau y La guerra de los mundos.

23 Escritor inglés, considerado como uno de los más importantes representantes del pensamiento moderno, debido a que sus obras criticaron los roles y convenciones sociales de inicios del siglo XX. Sus obra más reconocida es Un mundo feliz, novela que presenta un futuro pesimista en el que la sociedad es regida por el condicionamiento psicológico en el que la familia, la diversidad cultural, el arte, la ciencia, la religión, la filosofía y la literatura son eliminadas para alcanzar un estado de total felicidad.

24 Escritor y filósofo inglés, reconocido por sus novelas de ciencia ficción como Last and first men, Last men in London y Nebula maker. de un futuro distópico. De acuerdo con Lawrence Person:

Los personajes del cyberpunk clásico son seres marginados, alejados, solitarios, que viven al margen de la sociedad, generalmente en futuros distópicos donde la vida diaria es impactada por el rápido cambio tecnológico, una atmósfera de información computarizada ubicua y la modificación invasiva del cuerpo humano (1998, p.35).

Los protagonistas en el género de cyberpunk que suelen ser hackers, posthumanos etiquetados en el mundo en que viven, de visionarios, criminales, parias, inconformes, problemáticos, disidentes, cargando con un halo de anarquía sus personalidades y existencias. A pesar de lo anterior y de representar la disidencia del futuro, estos son manipulados: sus esfuerzos por estar en la posición de límite y de borde del control del poder (que no es el del estado, sino el de la gran corporación) resulta paradójica, ya que no logran escapar totalmente del control ejercido sobre ellos; luego entonces el cyberpunk en sí, no planteó una postura anarquista frente al problema del poder, más bien se planteó desde un nihilismo político, antropológico y epistémico (Sterling, 1998) que está de la mano con el nihilismo propuesto por Giovanni Vattimo en su libro "El fin de la modernidad: nihilismo y hermenéutica en la cultura posmoderna", y por Jean-Francois Lyotard en su libro "La condición postmoderna: informe sobre el saber".

El post-humano del cyberpunk también trae consigo la reflexión y las preguntas por la relación mente-cuerpo, el tiempo, la realidad, las formas de saber, la verdad, la estética del cuerpo humano, preguntas clásicas en toda la historia del quehacer filosófico. Un eje semántico que plantea la mayoría de las anteriores preguntas es el cuerpo post-humano. Dicho cuerpo es invadido con prótesis, tanto en los miembros motrices como 
en el sistema neuronal. La tecnología se instala en la piel o en las redes del sistema nervioso del cuerpo. Las drogas tecnológicas, la genética, el ciberespacio y la realidad virtual transforman la estructura del cuerpo, y los posthumanos invadidos y modificados por la tecnología tienen cuerpos modificados, creados y sustituidos por conexiones a otras realidades, hombres mitad carne mitad robot, y cyborgs $o$ androides que constituyen un nuevo cuerpo y mente (Dyaz, 1998).

En la estética de este tipo de CF, el cuerpo humano es usurpado por la corporación económica, o la máquina que gobierna tanto a humanos como a posthumanos (producida también por una empresa que busca el control total del planeta), para convertirlo en esclavo, en una batería de ciento veinte voltios para proveer de energía a las maquinas ${ }^{25}$. Las prótesis implantadas o los cuerpos cyborg $^{26}$ que usan la estructura del "cuerpo natural", configuran una corporeidad tecnificada y manufacturada, más producto de la ciencia que de los procesos biológicos naturales (Ferrara, 2008). Pero el cuerpo humano no es sin la mente, y aquí aparece el problema del cuerpo y la mente en dicha narrativa al introducirle a esa nueva corporeidad inteligencias artificiales, capaces no sólo de pensar, sino también de sentir emociones y deseos. EI humano ha inventado y creado una nueva especie, reviviendo con la tecnología el mito del monstruo del doctor Frankenstein, pero esta vez no lo ha hecho de pedazos de otros humanos, sino lo ha hecho de cables, cromo, metal, compuestos resistentes y cerebros artificiales.

La evolución del cyberpunk se podría identificar en tres etapas históricas a saber: clásica, intermedia y el postcyberpunk. Dentro de la primera clasificación

25 Dato extraído a partir de la exploración realizada de la película The Matrix.

26 Dato extraído a partir de la exploración realizada d de las películas: Yo robot, IA, y Terminator, encontramos películas como Blade runner, Tron y Videodrome (que presentaremos posteriormente); dentro del intermedio podríamos decir que se encuentran las más conocida de todas, la trilogía The Matrix de los hermanos Wachowski; y dentro de la tercera, se encuentran películas como Número Nueve (de la cual hablaremos más adelante), así como La isla de Michael Bay ${ }^{27}$, y todas las producidas del año 2000 en adelante. Cuando se habla de la obra cinematográfica de los hermanos Wachowski se está hablando del punto de inflexión del cyberpunk clásico al postcyberpunk en el cine. Por una parte, en la etapa clásica encontraremos una fuerte influencia de la novela negra, en el intermedio una evolución de la idea de la tecnología y en la tercera etapa una discusión más amplia del impacto de la tecnología en la humanidad y la naturaleza, el problema ambiental toma fuerza, los mundos pos-apocalípticos que nos muestran las películas la degradación de la naturaleza se convierte en tema y tópico de las narrativas: ciencia y tecnología, poder, y devastación de la naturaleza son el soporte discursivo de esta propuesta cinematografía. Un recorrido por los cambios históricos de este género implicara todo un plan de investigación.

\section{Variantes del género}

La etapa postcyberpunk generó en la exploración narrativa la diversificación del tipo de tecnología utilizada para el planteamiento de los argumentos, dentro de estas variantes tenemos:

- Steampunk: las películas se centran en las tecnologías de siglo XIX.

- Wirepunk: las películas se centran en las tecnologías de siglo XX.

27 Cineasta norteamericano, director y productor de películas de renombre como Armagedón, y la saga de Transformers. Sus películas se caracterizan por sus efectos visuales. 
- Biopunk: las películas se centran en las tecnologías que tienen que ver con la biología, ejemplos de este tipo de películas es Gattaca, del director Andrew Niccol y la cinematografía de David Cronenberg.

Para finalizar este apartado, trascribiremos la respuesta del escritor español Horacio Moreno ante la pregunta ¿Qué es el cyberpunk?

El movimiento Mirrorshades (anteojos espejados, cyberpunk) desde la década de los 80's se convirtió en un movimiento de culto. El negro y el cromo se erigieron como los colores emblemáticos de esta integración de mundo tradicionalmente separados: La tecnología de punta y la cultura callejera se amalgama para dar forma a esta vanguardia que trascenderá lo literario [...] El progreso técnico desintegra al sujeto racional, libre, moral y ético. El poder (del estado) ya no es piramidal, sino lineal, (la corporación) todos se controlan y son controlados (2003, p.33).

Las palabras de Horacio Moreno nos transportan a los apartados del libro "Vigilar y castigar" del filósofo Michel Foucault, cuando explica la arquitectura de panóptico y sus implicaciones en la formación de la sociedad disciplinaria. Dicha prisión diseñada a la sazón de la razón utilitarista del pensamiento liberal de Jeremías Bentham, no necesita de cadenas, grilletes, puertas en todas las celdas, y otros dispositivos, realizado un diseño de prisión eficiente que es llevado también al hospital, a la escuela, y más tarde a la fábrica (Foucault, 2002). Pero aquí la idea de Moreno (2003) consiste en mostrar la evolución del esquema del panóptico, siguiendo el párrafo citado, ahora no somos observados desde un mismo punto por un mismo vigilante, sino que a partir de los dispositivos tecnológicos todos custodiamos a todos, desaparecen los guardianes oficiales al convertirnos todos centinelas de todos, y de la misma manera que en
Foucault, el dispositivo es llevado a mas ámbitos de la vida humana, la tecnología que nos permite a todos controlar y al tiempo que todos somos controlados, en casi todos los ámbitos de la cotidianidad.

\section{FOTOGRAMA 2. EL ANÁLISIS SEMÁNTICO ESTRUCTURAL Y LA ESTRUCTURA ACTANCIAL}

A partir de la sociología de las estructuras simbólicas que se asocia con metodologías de la semántica es posible analizar datos e informaciones (materiales) de tipo cualitativo. El análisis estructural es una técnica del análisis semántico de los contenidos que va más allá del análisis del discurso, ya que esta considera que este es un contenedor de los significados. Por lo anterior, este tipo de análisis apunta a los contenidos de los discursos, permitiendo estudiar de forma científica la información cualitativa en niveles de abstracción más altos que el alcanzado a un nivel interpretativo-discursivo.

Esta técnica hace parte de los métodos usados por la ciencia general del signo: la semiótica. Dicha ciencia investiga los fenómenos significantes y de sentidos, sistemas de significación, lenguajes, discursos y los procesos a ellos asociados como la producción e interpretación. La producción de sentidos constituye una práctica importante de los humanos, o como los llama Charles Peirce, los procesos de semiosis ${ }^{28}$ que se vehiculizan mediante signos y se materializa en textos.

La semiótica o semántica estructural puede considerarse como una gramática de los lenguajes. Su interés analítico se concentra en el funcionamiento del sentido a partir del principio de la binariedad

28 La semiosis es cualquier forma de actividad, conducta o proceso que involucre signos. Incluyendo la creación de un significado. Es un proceso que se desarrolla en la mente del intérprete; se inicia con la percepción del signo y finaliza con la presencia en su mente del objeto del signo. “El proceso de la asociación de signos en la producción de significación interpretativa" (Chandeler, D. 1999, p. 23). 
del pensamiento y el lenguaje: la lógica humana es binaria, esto es, pensamos únicamente por oposición ${ }^{29}$, no existe sentido más que en la diferencia. Por otra parte, el análisis estructural es un método científico y a la vez una teoría sobre lo social que tiene sus antecedentes teóricos en la semántica estructural de A. J. Greimas (1976), y en la antropología estructuralista de Levi Strauss (1983). Su uso se ha hecho extensivo para el análisis del contenido de los discursos y de los modelos simbólicos que inciden en la producción de dichos discursos en el campo de la antropología y de la sociología (Martinic, 1992).

Desde la semántica estructural es que se ha realizado la apuesta analítica, para acércanos a la comprensión de los sentidos del cyberpunk y post-cyberpuk en el cine. En principio, la revisión de cada película del inventario estará llamada a consolidar dicho modelo semántico con la explicación de cada elemento del mismo, después de este gran paso, el siguiente tramo del camino apuntará a profundizar en las categorías que emergen de dichas apuestas narrativas en el cine: el cuerpo del posthumanismo, el poder de la firma y el estado como instrumento de dicho poder, el mercado laboral de las maquinas, el nuevo tipo de discriminación tecnológico, entre otros.

\section{La estructura actancial}

Una de las herramientas de estudio del análisis semántico son los modelos actanciales. El primer tipo de estructura fue propuesta por Vladimir Propp al realizar el análisis de los cuentos folclóricos rusos, encontrando treinta y un (31) elementos estructurales, es decir, 31 elementos que en todos los cuentos analizados se encontraban con diferentes nombres y con tra-

\footnotetext{
29 Oposición aquí no se refería a la opción dialéctica tradicional. Entiéndase opción en términos de la diferencia, por ejemplo: blanco más negro en posición a solo negro. Observemos la función semántica de la anterior afirmación. Opciones del negro = blanco + negro / negro.
}

mas diferentes (Propp, 1985). La evolución de los estudios narratológicos, y la discusión en torno a las funciones y las acciones de los personajes dentro del relato, de la cual participa Lévi-Strauss (1972) (uno de los padres del estructuralismo), reduce los 31 elementos identificados por el estudio, a seis elementos y tres ejes semánticos, propuesta realizada por A. J. Greimas en su semántica estructural (García, 1998).

En la Figura 1 se observa que el modelo actancial propuesto por Greimas está constituido por seis elementos y tres pares de binomios. 1) Sujeto/Objeto; 2) Destinador/Destinatario; 3) Ayudantes/ Oponentes.

En el primer binomio, un sujeto desea un objeto, objeto este que se refiere a una acción, persona o cosa, lo que posibilita la trama, ya que traza la trayectoria de la acción y la búsqueda del héroe, trayectoria llena de obstáculos que deben vencerse para poder avanzar. Para lograr lo anterior, es necesario que el segundo binomio entre en acción, cuando el destinador orienta el conjunto de hechos en beneficio de un destinatario, por lo que se constituye en el control de los valores y la ideología presentada en la trama. El tercer binomio se presenta cuando el sujeto es auxiliado por un ayudante y también es orientado por un oponente, lo que constituye que se facilite o se impida la comunicación, y no necesariamente son representados por personajes.

Para sugerir un ejemplo, en la trilogía de la película The Matrix de los hermanos Andy y Larry Wachowski, el personaje Neo interpretado por Keanu Reeves sería dicho sujeto. Para seguir con este ejemplo, su objetivo es liberar a los posthumanos que sirven como biobaterías (esclavos que producen energía) dentro de la Matrix, liberando al tiempo a lo últimos humanos que habitan en la ciudad de Zion. Es decir, que el objeto en esta narración es la liberación. ¿La libertad de quiénes, para 
quién, y cuáles son sus destinatarios? Pues los humanos y posthumanos que viven en Zion y los potshumanos que viven como biobaterias conectadas a la realidad virtual creada por la Matrix. Los oponentes de Neo son los agentes, las máquinas centinelas que persiguen la nave capitaneada por Morfeo, y Tank que los traiciona a cambio de volver a la Matrix. Los ayudantes son la pitonisa, Neo, Triniti, el resto de la tripulación de la nave Nebuchadnezzar y los habitantes de Zion. En esta narración el destinador es la misma Matrix, dejando ver el argumento de la película la postura nihilista del cyberpunk (ver Figura 2)

FOTOGRAMA 3. LA ESTRUCTURA ACTANCIAL DEL CYBERPUNK Y POSTCYBERPUNK

Como cualquier narración, inclusive las teóricas, las historias tramadas y narradas en el cine por los géneros cyberpunk y postcyberpunk comparten una estructura actancial. Identificar esta estructura es uno de los objetivos de nuestra indagación, ya que esta podría significar una síntesis valiosa de cómo el séptimo arte, desde una perspectiva nihilista del futuro, crea una visión crítica del impacto de la tecnología en la sociedad, convirtiéndose la reflexión del cyberpunk y postcyberpunk en la antesala de la filosofía de la tecnología y los estudios de CTS. Como se planteó desde la introducción, la estructura que presentamos en este texto es provisional, ya que por el momento tan sólo se han catalogado 120 películas, se han encontrado 75 , se ha realizado una primera observación de 60 y observado y analizado con mayor detenimiento 40 de estas últimas.

Como se observa en la Figura 3, el sujeto es una anomalía y puede ser un humano o un posthumano. Identificamos a este como anomalía, en la medida en que el sujeto se sale de la norma establecida sin percibirlo de una vez, sin esperárselo, su rol parece asignado aleatoriamente; en un primer momento es un accidente de las situaciones y acciones de la trama, pero cuando las historias están en plena epicrisis descubrimos que dicha anomalía es producida por el mismo sistema poder o por error y/o prevención (creado como salvaguarda) de su inventor-creador (científico). El objeto que siempre persiguen los sujetos (héroes) del cyberpunk y postcyberpunk es la libertad, la liberación del yugo de la máquina, de la gran corporación, del poder reinante y tiránico, en beneficio de los humanos y posthumanos esclavizados de múltiples maneras (Destinatarios).

En la línea de acción del Sujeto (anomalía), el objeto (libertad), y los destinatarios (humanos y posthumanos), la investigación ha identificado que el elemento destinador genera el nihilismo asociado a dicha narrativa, dado que este es el mismo poder que subyuga, o es el inventor-científico que ha estado al servicio de dicho poder. En cuanto a los ayudantes (simples seguidores), como los oponentes (guardianes y policías del poder tecnológico), son simples peones/ seguidores al servicio del sujeto o del destinador. Poco se ha podido avanzar en estos dos elementos de este modelo actancial provisional, como estructuras de significado que lleven a una reflexión profunda. Debemos aclarar en este punto que la estructura mejor lograda es la de libertad, las otras aún están identificadas de forma tentativa, dado el estado actual de la investigación.

\section{FOTOGRAMA 4. LA TELEVISIÓN DEL CONTROL NEURONAL: VIDEODROME}

Max Renn, director y accionista de un canal de televisión, es expuesto públicamente con una entrevista sobre el contenido violento y obsceno que trasmite su canal. En esta es acusado por el contenido que emite, pero él se defiende de la perio- 
Figura 1. Estructura actancial greimasiana

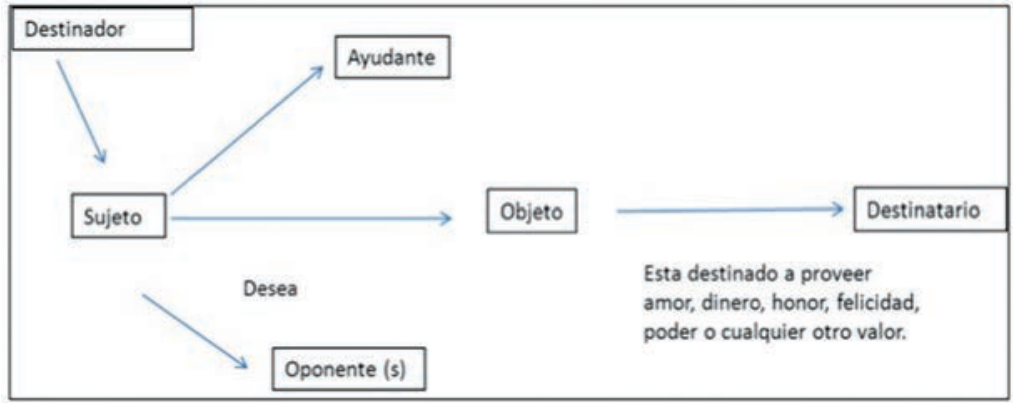

Fuente: Semántica estructural: investigación metodológica, Greimas, A.,1976.

Figura 2. Estructura actancial de la trilogía de la Matrix

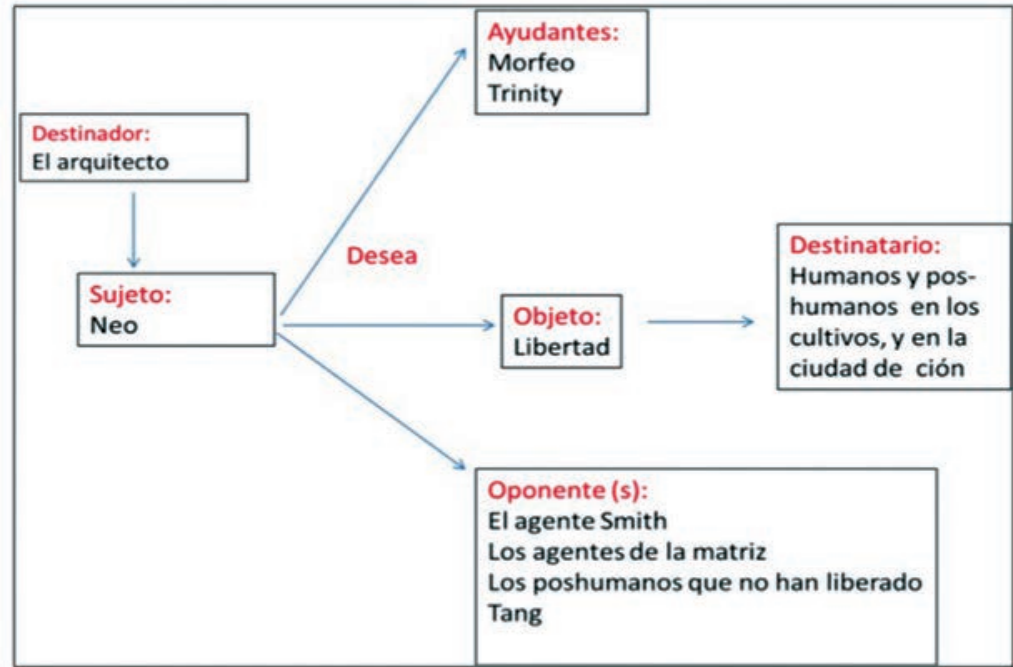

Fuente: autores

Figura 3. Estructura actancial provisional del cyberpunk y postcyberpunk en el séptimo arte

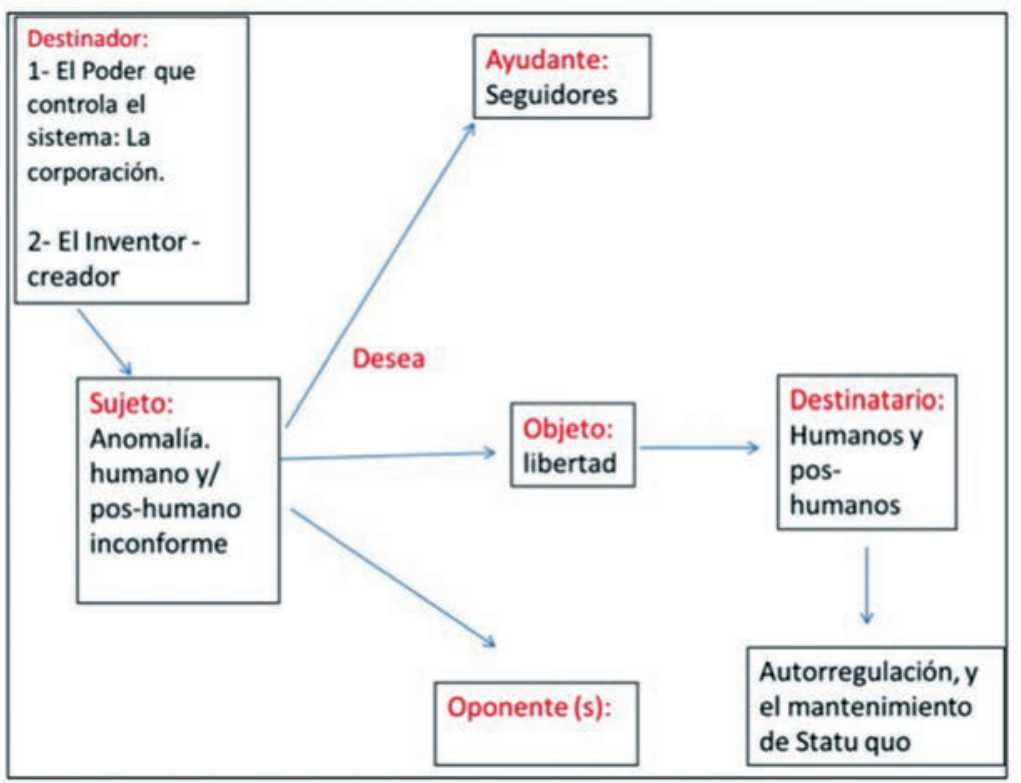


dista con el argumento de que este sirve de válvula de escape, y que el deshago de cierta tensiones podrían evitar la violencia real en las calles. El singular director de la cadena de televisión sigue buscando contenidos sexuales y violentos para su canal a través de un pirata de señales, quien le proporciona información de diferentes partes del mundo. El pirata de señales, captura y grava unos programas donde son sodomizadas mujeres, pero las imágenes son reales y no son actuaciones, las actrices disfrutan del suplicio. Dichos contenidos seducen la curiosidad de Max Ren, este le pide que rastree dicha señal -videodrome-, al tiempo que en su apartamento el observa las cintas y empieza a experimentar cambios en su mente y cuerpo. Poco a poco, descubre que los programas infectan la mente del que los observa, y que él empieza a ser controlado neuronalmente por la señal (Sánchez, 2007).

Cronenberg, quien es uno de los directores emblema del cyberpunk, produce y dirige esta película clásica del género. En esta se plantea la forma como la televisión, y de paso los medios de comunicación de masas, manipulan las vidas de sus televidentes; dichos medios, como brazos y herramientas del poder de la gran firma-corporación, pueden desplegar un poder controlador a nivel neuronal. La película, como en casi todas las dirigidas por el mencionado director, muestra como el cuerpo cambia con la relación que establece el hombre con la tecnología. En Videodrome se observa el tema de la mutación del humano al monstruo-humano, o para decirlo de mejor forma, el post-humano. La triada cuerpo-mente-tecnología es la clave y el vehículo de la metamorfosis del humano, tema que una y otra vez este director ha explorado en sus películas, como en $\mathrm{La}$ Mosca en la que el productor trabaja la mutación como tema e hilo conductor de la misma, es complejizado por la introduc- ción de los conceptos de poder y control (Braidotti, 2005).

En relación al tópico del control y el poder, Cronenberg usa la subjetividad televisual y el capital multinacional como metáfora para referirse a la mezcla de los códigos (Kauffman, 1998). En ese sentido, la especulación entra en juego, ya que esta representa tanto contemplación como lucro cuando el B. Convex, director ejecutivo de la multinacional Spectacular Optical, fabricante de artículos que van desde vasos desechables hasta proyectiles teledirigidos para diversas organizaciones, decide junto a otros socios deshacerse de O'Blivion, inventor de Videodrome, para usar esta como un dispositivo de control mental, transmitido a través del inmoral canal de televisión por cable de Renn. Videodrome se convierte entonces en ese controlador mental que hace que la televisión convierta a sus televidentes en productos para sus anunciantes, haciendo que los primeros sean más fáciles de manipular y moldear.

\section{FOTOGRAMA 5. LOS NUEVE MUÑECOS DE TRAPO: UNA TEORÍA MORAL POS-APOCALÍPTICA}

Un ejemplo de postcyberpunk es una película producida por Tim Burton ${ }^{30} \mathrm{y}$ dirigida por Timur Bekmambeto ${ }^{31}$, en el año 2009: Numero 9. A pesar que el personaje 9 es el héroe, todos los otros 8 personajes (post-humanos) cumplen una función indispensable en la trama de la película. Todo el grupo de posthumanos y su creador hacen parte de una misma unidad ética, que generan dentro del film

30 Escritor, director y productor de cine norteamericano célebre por sus películas en las que se representan mundos imaginarios con escenarios góticos y oscuros. Entre sus producciones más notables se encuentran: El joven manos de tijera, Charlie y la fábrica de chocolate, Batman y Batman regresa, El gran pez, y las animaciones Frankieweenie y el cadáver de la novia.

31 Productor y director de cine ruso, conocido por las películas Guardianes de la noche y Guardianes del día. Ha colaborado en múltiples producciones con Tim Burton. 
un debate moral. Además de lo anterior, esta película nos recuerda al mito del monstruo creado por el Doctor Víctor Frankenstein, fuente de la narrativa del cyberpunk clásico. El postcyberpunk conserva la esencia de su antecesor de los ochenta, a pesar de suavizar el barroquismo visual e introducir reflexiones éticas a la descripción clásica de los problemas filosóficos ${ }^{32}$. Frente a lo planteado anteriormente, uno los padres del cyberpunk como movimiento literario, ideológico y filosófico, Bruce Sterling citado por Ferrara, dice:

En un análisis cyberpunk, Frankenstein es ciencia-ficción humanista. Promueve el dictamen romántico de que hay cosas que el hombre no debe conocer. No hay mecanismos meramente físicos para esta ley de la alta moral, su alcance trasciende el entendimiento de los mortales, es algo emparentado con la voluntad divina. Ahora imaginemos una versión cyberpunk de Frankenstein... el Monstruo podría ser el bien costeado proyecto de Investigación y Desarrollo de alguna corporación global. El Monstruo podría llevar a cabo sangrientas incursiones, preferentemente contra transeúntes ocasionales. Pero incluso así, nunca le permitirían escaparse a pasear por el Polo Norte, profiriendo profundidades byrónicas. Los monstruos del cyberpunk nunca se desvanecen tan convenientemente. Ya están sueltos por las calles [...] El Monstruo tendría un copyright, a través de las leyes genéticas y sería producido en todo el mundo a muchos miles. Pronto los Monstruos tendrían piojosos trabajos nocturnos, atendiendo restaurantes de fast food (2008, pp. 2007-2008).

32 Una revisión del catálogo de películas dejan ver que el cyberpunk clásico se mueve en los problemas de tipo: Epistemológico, antropológico, ontológico y político. Por ejemplo, los problemas típicos planteados en los relatos plantean problemas filosóficos como: El cuerpo y la mente, el posthumanismo creado por la tecnología, la utilización del poder del estado por parte de la corporación económica.
En un mundo post-apocalíptico, nueve pequeños seres de trapo emprenden la labor de salvar el mundo, gracias a la destrucción propiciada por la "Gran Máquina activa". Esta máquina es un generador de energía de otras máquinas que están en guerra contra la humanidad. El mundo es destruido y le sobreviven nueve criaturas a las que un científico infundió vida poco antes de dicha destrucción. Número 9, es el post-humano anomalía, que arrastra a las otras 8 criaturas a liberase de la gran máquina. La creatividad de un ingeniero, la erudición y sabiduría de un lector, las visiones del artista, el valiente guerrero, la fuerza física, son valores personificados por cada una de las criaturas, generando la interrelación de cada elemento una discusión moral, pos-apocalíptica.

En este largometraje animado se presenta narrativamente la lucha de las máquinas, vencedoras de la guerra contra la humanidad, la lucha de post-humanos contra ellas. La esperanza es algo que casi no aparece en el cyberpunk clásico, en esta película sí lo hace, y en el fondo de los sentidos de la narración se desata la discusión moral, ya que cada uno de los personajes representa aspectos de la condición humana:

Numero 1: cobarde, egocéntrico, religioso y dogmático. Proyecta la figura de un ministro tiránico. Es el responsable de la existencia de las criaturas sobrevivientes, pero a partir del miedo y la instauración de estrechos límites a la libertad.

Numero 2: se trata de un anciano inventor de personalidad paternal. Provee de instrumentos y herramientas al grupo, revelando la creatividad del científico.

Números 3 y 4: gemelos, eruditos que clasifican y memorizan todo lo que están al alcance de ellos. Son tímidos pero al tiempo curiosos y rápidos para comprender las situaciones. Son mudos, y por lo tanto, representan la debilidad física. 
Numero 5: a pesar de ser cobarde y dependiente, es un ingenioso ingeniero, representa la generosidad y amistad incondicional. Es casi como un dador de soluciones, es un inventor. También es el cirujano de los post-humanos.

Numero 6: representa al espíritu artístico, nervioso y tímido, torpe e inocente e identificado como "loco" por el resto del grupo, por dibujar una y otra vez las mismas figuras.

Numero 7: es la mujer guerrera valiente y autosuficiente, solitaria, rebelde, con templanza, la valentía, la fuerza y la elegancia caracterizan a esta criatura post-humana.

Numero 8: es grande y fuerte, representa la materialidad. Su personalidad está guiada por el uso de la "fuerza bruta" y el placer.

Numero 9: Es el conjunto de todos los valores y elementos de las nueve criaturas.

\section{FOTOGRAMA 6. TO BE CONTINUED (A MANERA DE CONCLUSIÓN)}

A medida que avanzamos en la observación y análisis de las narraciones del cyberpunk llevadas al cine, observamos que todos sus héroes o mejor dicho el actante sujeto, deciden sobre la estructura dicotómica libertad/sujeción. La elección por la libertad, tanto la propia como la de humanidad o/y posthumanidad, enruta al sujeto en la búsqueda de esta. Mientras en algunas narraciones dicha búsqueda despliega el concepto la sujeción, como en el caso de Videodrome, otras profundizan sus argumentos en el de libertad, como en la Matrix. La dicotomía libertad/ sujeción constituye el actante objeto de todas la narraciones de este género narrativo.

Siguiendo el hilo conductor, el concepto de libertad del cyberpunk está consti- tuido por los elementos libertad/sujeción, los cuales están en tensión en cada una de las narraciones permitiendo la matización de las ideas en torno a la libertad. Dicha estructura de sentido, junto con el actante sujeto (anomalías de los sistemas), son las más fáciles de identificar, ya que estas constituyen la angustia y posibilidad que proveen las tecnologías a los humanos y posthumanos. En este punto, la ficción se encuentra con nuestras vidas.

El 5 de agosto de 2013, Victoria Solano compartió su documental versión para YouTube, 9.70. Dicho documental narra y denuncia la incautación y destrucción de semillas por parte del gobierno a un grupo de campesinos, y abre el debate de los colombianos al tema de la seguridad alimentaria, y el control genético de la semilla que la multinacional Monsanto ha propiciado en todo el mundo. A pocos días de acercarse las elecciones presidenciales de Colombia en el 2014, la prensa denuncia las estrategias oscuras y soterradas de uno de los candidatos de hackear las cuentas de redes sociales del candidato-presidente, y el espionaje de personajes vinculados a las negociaciones en la Habana, Cuba, con el fin de sabotear tanto el proceso electoral como las negociaciones en la isla. Las noticas de la realidad política de un país, o la de cualquier desarrollo médico o de cualquier ramo de la tecnología, como los avances médicos que proveen prótesis y hacen biónicos a los humanos, como Pistorius (que con sus "piernas zancos" pudo llegar a ser uno de hombres más veloces de la tierra), nos entrecruzan con las ficciones del cyberpunk, y quedamos de cara a la reflexión de los nuevas formas de sujeción y sus respectivas resistencias, al tiempo que observamos la metamorfosis y mutación de "lo humano".

Después de aumentar el inventario cinematográfico de esta investigación, el camino a seguir es realizar una profundización de cada una de las estructuras del modelo actancial del cyberpunk, al tiempo que se debe responder las preguntas de 
la relaciones de estas estructuras en los sentidos de estas narraciones de ficción, con nuestras vidas. El primer capítulo de esta saga queda abierto para completar su misión.

\section{REFERENCIAS}

Aldiss, B. (1963). Cuando la tierra esté muerta. Ediciones: Agapea

Aldiss, B. (1965). Un mundo devastado. Ediciones: Uniliber.

Aldis, B. (1962). Invernáculo. Ediciones: Iberlibro.

Burgos, A. (2011). Blade Runner. Lo que Decard no sabía. Madrid: Ediciones AKal, S.A.

Chandeler, D. (1999). Semiótica para principiantes. Quito: Editorial Abye-Yala.

Dyaz, A. (1998). Cyberpunk. Una Nueva Filosofía. Mundo Artificial: Internet, ciberpunk clonación y otras palabras mágicas. Madrid: Ediciones Temas de hoy S.A.

Ferrara, G. (2008). El cuerpo humano entre el arte y los medios de masas en el tránsito del siglo XX al XXI. [Plasencia Climent, C. dir. Tesis doctoral]. Universitat Politècnica de València. Departamento de Dibujo.

Foucault, M. (2002). Vigilar y castigar: nacimiento de la prisión. Buenos Aires: Siglo XXI Editores.

Greimas, A. (1976). Semántica estructural: investigación metodológica. Madrid: Editorial Gredos.
Lévi-Strauss, C. (1972). Polémica Lévi-Strauss-Propp. Madrid: Editorial Fundamentos. Madrid: Ediciones Universidad Salamanca.

Martinic, S. (1992). Análisis estructural: Presentación de un método para el estudio de lógicas culturales. Santiago de Chile: CIDE - Centro de Investigación y Desarrollo de la Educación.

Moreno, H. (2003). Cyberpunk más allá de Matrix. Barcelona: Círculo Latino.

Naief, Y. (1994) Los sueños mecánicos de las ovejas electrónicas. El cyberpunk en el cine. México: Editorial Juan Pablos.

Pascual, J., Telo A., Vidal M. (2005). Comunicación audiovisual digital: nuevos medios, nuevos usos, nuevas formas. Barcelona: Editorial UOC.

Person, L. (1998). Notas hacia un Manifiesto de Postcyberpunk. New York: Nova Express.

Propp, V. (1985). Morfología del cuento. Madrid: Ediciones Akal.

Sánchez, S. (2007). Películas Clave en el cine de cienciaficción. Barcelona: Ediciones Robinboock.

Santana, C. (2001). El inicio del siglo XX (1914-1926): La ciencia Ficción en los vehículos de la cultura literaria popular. Costa Rica: Editorial Universidad de Costa Rica.

Sterling, B. (1994). El cyberpunk en los noventas. En: Umbrales: Revista mexicana de ciencia ficción fantasía y horror, (10), 10-21.

Sterling, B. (1998). Mirrorshades: Una antología del ciberpunk. Bruce. Madrid: Ediciones Siruela, S. A. Braidotti, Rosi. (2005). Metamorfosis. Hacia una teoría materialista del devenir. Madrid: Ediciones Akal, S. A. 